\title{
ANN Based Constant Frequency-Unified Power Quality Conditioner
}

\author{
P. Jeno Paul and T. Ruban Deva Prakash \\ Electrical and Electronics Engineering, Noorul Islam University, Tamil Nadu, India
}

\begin{abstract}
The aim of this study is to maintain the constant frequency in the utility using constant frequency unified power quality conditioner with (Artificial Neural Network) ANN controller. A Constant Frequency Unified Power Quality Conditioning system (CF-UPQC) consists of a Unified Power Quality Conditioner (UPQC) and a matrix converter based frequency changer. UPQC is a combination of series active and shunt active filter. The series active filter and shunt active filters are used to compensate the voltage, current imbalance and harmonics. Frequency converter (matrix converter) is used to regulate the supply frequency when it varies beyond the power quality limit. The performance of the CF-UPQC is compared with ANN controller against conventional controller.
\end{abstract}

$\underline{\text { Key words: } \mathrm{CF}-\mathrm{UPQC} \text {, matrix converter, active filter, ANN controller, Matlab/Simulink, combination, India }}$

\section{INTRODUCTION}

Unified power quality conditioner is an advanced concept in the area of power quality control (Fig. 1). The basic working principle of unified power quality conditioner is based on series active filter and parallel active filter power converters that shares a common DC link (Watanabe and Aredes, 2002). Unified power quality conditioner is used to compensate voltage sag, voltage swell (Mauricio and Fernandes, 2009) and current harmonics (Benslimane et al., 2006). It is also used to compensate an impact on the reactive power (Chung and Deohan, 2005) through series voltage source inverter and shunt voltage source inverter. In order to avoid the switching oscillation, passive filters are replaced at the output of each inverter. At the output of shunt inverter a high pass 2 nd order LC filter is placed and the output of series inverter low pass 2 nd

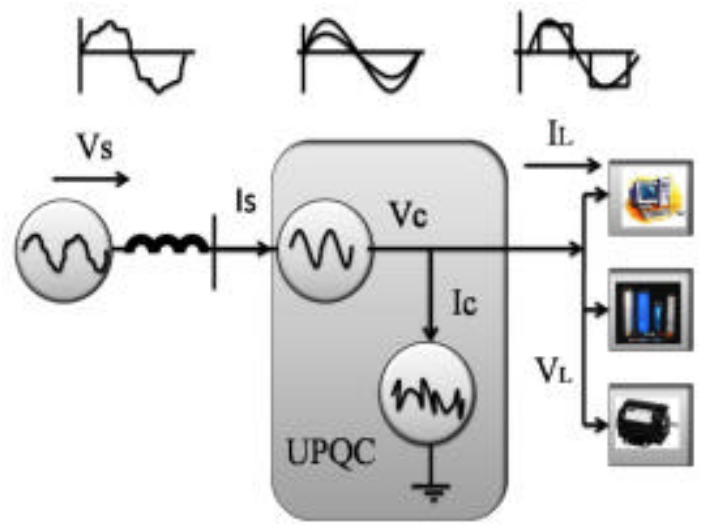

Fig. 1: Basic configuration of unified power quality conditioner order LC resonance filter is allocated (Graovac et al., 2000). UPQC controller provides the compensated voltage through the UPQC series inverter and conditioning the current through the shunt inverter by instantaneous sampling of source voltage and load current. The reference current is compared with the shunt inverter output current $\left(I_{a}-I_{c}\right)$ and they are fed in to hysteresis type (PWM) current controller. There are some problems with UPQC. UPQC cannot compensates supply frequency variations. As the supply frequency changes, the UPQC will not compensate or regulate the supply frequency as there is no device to regulate the supply frequency. To overcome this problem, CFUPQC is introduced recently using PI controller (Jeno Paul et al., 2011).

\section{FREQUENCY QUALITY INDICES}

Power quality is the set of limits or conditions of electrical properties that allows electrical devices to function in their planned manner without the loss of performance (Monedero et al., 2007). Without the proper power, an electrical utility or load may malfunction, fail permanently or not operate at well. The main power quality problems are voltage sag, voltage swell, voltage harmonics, current harmonics and supply frequency variations (Mishra et al., 2008). The deviation of the power system fundamental frequency from its specified nominal value is defined as power frequency variation. If the balance between generation and demand is not maintained the frequency of the power system will deviate because of change in the rotational speed of electromechanical generator. The

Corresponding Author: P. Jeno Paul, Electrical and Electronics Engineering, Noorul Islam University, Tamil Nadu, India 
amount of deviation and its duration of the frequency depend on the load characteristic and the response of the generation control system to load changes. Faults of power transmission system can also cause frequency variation outside of the accepted range for normal steady state operations of the power system.

Effects of variation of voltage and frequency on the performance of induction motors: Induction motors are time operated on circuits of voltage or frequency other than for which the motors are rated. Under such conditions, the performance of the motor will vary from the rating. The following is a brief statement of some operating results caused by small variations of voltage and frequency and it also indicates the general changes produced by the variations in operating conditions. With a $10 \%$ increase or decrease in voltage given on the nameplate, the heating at rated horsepower load may increase.

Such operation for extended periods of time may accelerate the deterioration of the insulation system. In a motor of normal characteristics at full rated horsepower load, a 10\% increase of voltage given on the nameplate would usually result in a lowering of power factor. A $10 \%$ decrease of voltage below that given on the nameplate would usually give an increase in power factor. The locked-rotor and breakdown torque will be proportional to the square of the voltage applied. An increase of $10 \%$ in voltage will result in a decrease of slip of about $17 \%$ while a reduction of $10 \%$ will increase the slip about $21 \%$. Thus if the slip at rated voltage were $5 \%$, it would be increased to $6.05 \%$ if the voltage were reduced $10 \%$. A frequency higher than the rated frequency usually improves the power factor but decreases locked-rotor torque and increases the speed and friction and windage loss. At a frequency lower than the rated frequency, the speed is decreased, locked-rotor torque is increased and power factor is decreased.

For certain kinds of motor load such as in textile mills, close frequency regulation is essential. If variation in both voltage and frequency occur simultaneously, the effect will be superimposed. Thus if the voltage is high and the frequency is low, the locked-rotor torque will be greatly but the power factor will be decreased and the temperature rise increased with normal load. The foregoing facts apply particularly to general-purpose motors. They may not always be true in connection with special-purpose motors built for a particular or as applied to very small motors.

While general-purpose alternating-current poly phase 2, 4, 6 and 8 pole, $60 \mathrm{~Hz}$ integral-horsepower induction motors are not designed to operate at their $60 \mathrm{~Hz}$ ratings on $50 \mathrm{~Hz}$ circuits, they are capable of being operated satisfactorily on $50 \mathrm{~Hz}$ circuits if their voltage and horsepower ratings are appropriately reduced. When such $60 \mathrm{~Hz}$ motors are operated on $50 \mathrm{~Hz}$ circuits, the applied voltage at $50 \mathrm{~Hz}$ should be reduced to $5 / 6$ of the $60 \mathrm{~Hz}$ horsepower rating of the motor. The other performance characteristics for $50 \mathrm{~Hz}$ operation are as follows:

Speed: The synchronous speed will be $5 / 6$ of the $60 \mathrm{~Hz}$ synchronous speed and the slip will be $6 / 5$ of the $60 \mathrm{~Hz}$ slip.

Torque: The rated load torque in pound-feet will be approximately the same as the $60 \mathrm{~Hz}$ rated load torque in pound-feet. The locked-rotor and breakdown torques in pound-feet of $50 \mathrm{~Hz}$ motors will be approximately, the same as the $60 \mathrm{~Hz}$ locked-rotor and breakdown torques in pound-feet.

Locked-rotor current: The locked-rotor current (amp) will be approximately $5 \%<60 \mathrm{~Hz}$ locked-rotor current (amp). The code letter appearing on the motor nameplate is used to indicate locked-rotor KVA per horsepower applies only to the $60 \mathrm{~Hz}$ rating of the motor.

Service factor: The service factor will be 1.0 .

\section{PROPOSED SYSTEM}

Figure 2 shows the proposed improved configuration of constant frequency-unified power quality conditioner. This modified unified power quality conditioner concepts enables the PWM

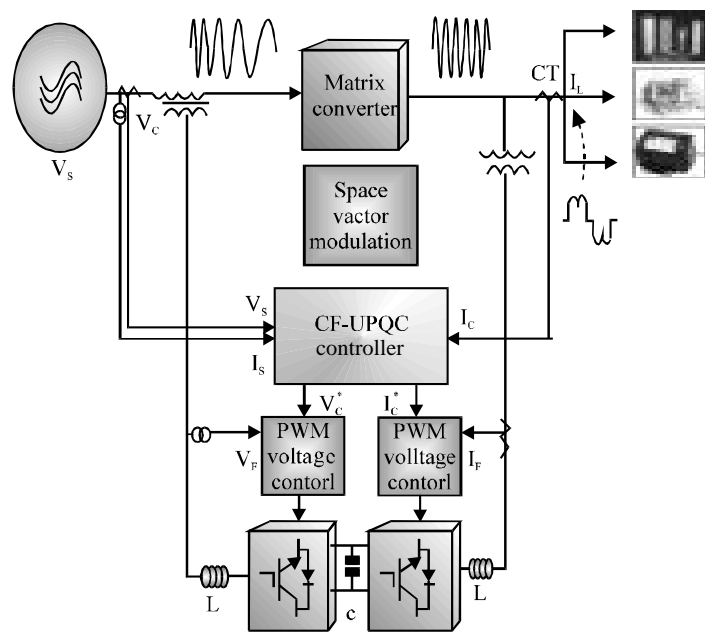

Fig. 2: Proposed configuration of CF-UPQC 
converter to perform active filtering purpose and matrix converter also performs the function of frequency regulator. The compensation principle of the CF-UPQC will be explained in the coming sections B-D. The proposed unified power quality conditioner has to satisfy the following requirements. Reactive power is maintained at minimum value. The load voltage should be maintained at the rated supply voltage. Maintain the input current with very low harmonic content. Assure the supply frequency is permissible within the power quality limits. The simulations result will be presented to validate the proposed CF-UPQC. Modified configuration of UPQC consists of shunt active filter, series active filter, matrix converter shown in Fig. 3. CF-UPQC is similar to the UPQC expect the frequency changing section. The frequency converter is achieved by matrix converter. The main advantage of frequency converter is as follow. Matrix converter can only increase or decrease the frequency instead of cyclo-converter.

Here, there is no dc storage element. So, losses are minimized and Harmonics also minimized. UPQC has the potential drawbacks in the hybrid filtering performance as its filter in characteristics depends on load impedance and supply CF-UPQC is matrix converter regulates the frequency of supply voltage. CF-UPQC series active filter is used for compensating the voltage harmonics and voltage imbalance. The CF-UPQC consists of Parallel Active Filter (PAF) that eliminates load harmonics and compensates load reactive power. In addition, the shunt active filter converter supplies the AC-DC power and is fed to common DC link. The control equation is:

$$
I_{p f}=G . I_{L} \rightarrow|G(j \omega)|=\left\{\begin{array}{c}
0, \omega=\omega 1 \\
1, \omega=\omega h
\end{array}\right.
$$

Where:

$\mathrm{G}=$ Control function

$\omega=$ Fundamental frequency

$\mathrm{I}_{\mathrm{L}}=$ Load current

$\mathrm{I}_{\mathrm{pf}}=$ Parallel filter input current components for compensation are extracted from load current and load voltages using dq theory while the converter is a current controlled device using $20 \mathrm{kHz}$ clocked hysteresis band

Series Active Filter (SAF) compensates supply harmonics flicker, voltage sag/swell and unbalance load harmonics to flow in to the parallel filter. Control equation is:

$$
\mathrm{U}_{\mathrm{sf}}=\mathrm{K} \cdot \mathrm{G} \cdot \mathrm{I}_{\mathrm{sh}}+\mathrm{U}_{\mathrm{comp}}
$$

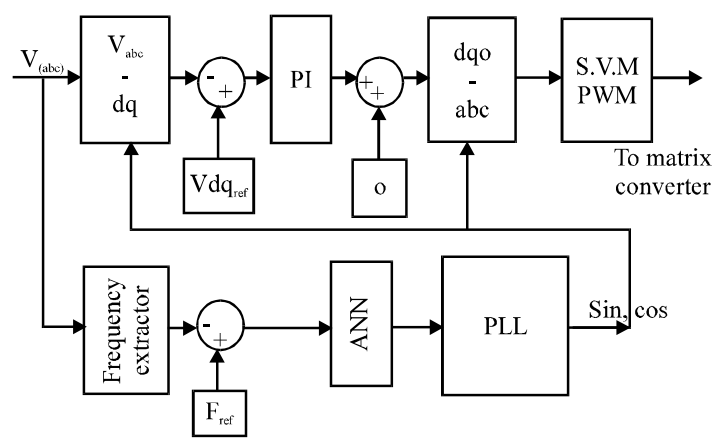

Fig. 3: Proposed fuzzy based control system of the frequency changer block (CF-UPQC)

Where:

$\mathrm{K} \quad$ = Regulator gain

$\mathrm{U}_{\mathrm{sf}}=$ Series filter voltage

$\mathrm{I}_{\mathrm{sh}} \quad=$ Harmonic supply current

$\mathrm{U}_{\text {comp }}=$ Compensation voltage needed to remove supply voltage imperfection

$\mathrm{I}_{\mathrm{sh}} \quad=$ Extracted to dq theory

CF-UPQC frequency regulator system-ANN controller: The matrix converter consists of nine bi-directional switches arranged in three groups each being associated with an output line. This bi-directional switches arrangement connects any of the input lines to any of the output lines.

A matrix with elements $S_{i j}$, representing the state of each bi-directional switch (on $=1$, off $=0$ ) can be used to represent the matrix output voltages $\left(\mathrm{V}_{\mathrm{u}}-\mathrm{V}_{\mathrm{w}}\right)$ as function of inverters. At the same time, series active filter compensates the voltage problems. Figure 3 shows the control system of the frequency regulator. The matrix converter is controlled by space vector modulation. The reference voltage is used to control the regulation of output frequency. The supply frequency $\mathrm{V}_{\mathrm{f}(\mathrm{abc})}$ is sensed by the frequency counter. It is compared with the reference frequency $V_{\mathrm{f}(\mathrm{ref})}$ and extract the error value. The compensated value is produced by the ANN controller and the compensated frequency is fed to the Phase Locked Loop (PLL). When the supply frequency is varied beyond the power quality limit, the frequency controlling system (matrix converter) changes the required PLL frequency from ANN controller. The detailed ANN control system is described further. The conventional control (PI), system is not suitable for non linear systems. ANN is essentially a cluster of interconnection of nonlinear elements of very simple form that possess the ability of learning and adaptation. These networks are characterized by their topology, the way in which they 
communicate with their environment, the manner in which they are trained and their ability to process information. Their ease of use, inherent reliability and fault tolerance has made ANNs a viable medium for control. An alternative to fuzzy controllers in many cases, neural controllers share the need to replace hard controllers with intelligent controllers in order to increase control quality. A feed forward neural network works as a compensation signal generator. This network is designed with three layers. The input layer with seven neurons, the hidden layer with twenty one and the output layer with three neurons. Activation functions are chosen by tan sigmoidal and pure linear in the hidden output layers, respectively. The training algorithm is used by Levenberg Marquardt Back Propagation (LMBP). The Matlab programming of ANN training is given as below:

net $=$ newff $(\operatorname{minmax}(P),(7,21,3)$,

\{,tansig", "tansig“, "purelin"\}, "trainlm"); net.train Param. show $=50$;

net.train Param. $1 \mathrm{r}=0.05$;

net.train Param.mc $=0.95$;

net.train Param. $1 \mathrm{r}$ inc $=1.9$;

net.train Param.lr_ dec $=0.15$;

net.train Param. epochs $=1000$;

net.train Param.goal $=1 \mathrm{e}-6$;

[net, tr] = train $($ net,P,T);

$\mathrm{a}=\operatorname{sim}($ net, $\mathrm{P})$;

gensim (net, -1);

The compensator output depends on input and its evolution. The chosen configuration has seven inputs, three each for reference frequency and source frequency, respectively and one for output of error (PI) controller. The neural network is trained for outputting fundamental reference currents. The signals is obtained and fed to PLL. PLL only determines the phase angle of out put voltage of the matrix converter.

Control system of the shunt CF-UPQC: Figure 4 shows the shunt inverter controlling block diagram of CF-UPQC using synchronous reference frame theory where the loads current are $I_{a}-I_{c}$ is given. The measured currents of load are transferred in to dqo frame using sinusoidal functions through dqo synchronous reference frame conversion. The sinusoidal functions are obtained through the grid voltage using Phase Locked Loop (PLL). Here, the currents are divided into ac and dc components:

$$
\mathrm{I}_{\mathrm{id}}=\overline{\mathrm{I}}_{\mathrm{id}}+\tilde{\mathrm{I}}_{\mathrm{id}}
$$

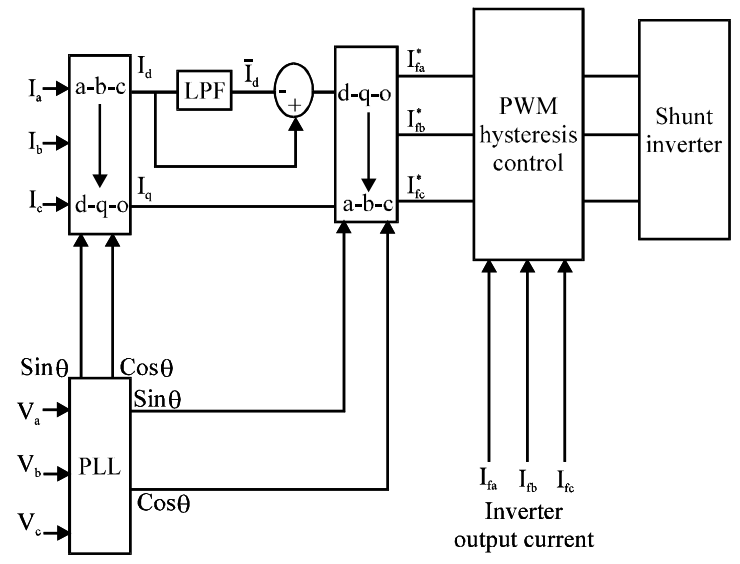

Fig. 4: Control system of the shunt CF-UPQC

$$
\mathrm{I}_{\mathrm{iq}}=\overline{\mathrm{I}}_{\mathrm{iq}}+\tilde{\mathrm{I}}_{\mathrm{iq}}
$$

In Eq. 3 and $4, i_{d}$ and $i_{q}$ are the real and reactive components. $\mathrm{AC}$ components and $\mathrm{DC}$ elements can be derived by low pass filter. $\overline{\mathrm{I}}_{\mathrm{d}}, \overline{\mathrm{I}}_{\mathrm{iq}}$ are the dc components and $\tilde{I}_{\mathrm{id}}, \tilde{\mathrm{I}}_{\mathrm{iq}}$ are the ac components of $\mathrm{I}_{\mathrm{id}}, \mathrm{I}_{\mathrm{iq}}$. The control algorithm corrects the systems power factor and compensates all the current harmonica component by generating the reference currents given in Eq. 5:

$$
\begin{aligned}
& \mathrm{I}_{\mathrm{fd}}^{*}=\tilde{\mathrm{I}}_{\mathrm{id}}^{*} \\
& \mathrm{I}_{\mathrm{fq}}^{*}=\tilde{\mathrm{I}}_{\mathrm{q}}^{*}
\end{aligned}
$$

The reference current is transferred in to (a_b_c) frame through reverse conversion of synchronous reference frame. Resulted reference current $\left(\mathrm{I}_{\mathrm{fa}}^{*}-\mathrm{I}_{\mathrm{fc}}^{*}\right)$ and the output current of shunt inverter $\mathrm{I}_{\mathrm{fa}}, \mathrm{I}_{\mathrm{fc}}$ are fed to the hysteresis band controller. Now the required controlling pulses are generated and the required compensation current is generated by the inverter applying these signals to shunt inverters power switch gates.

CF-UPQC series inverter control system: Figure 5 shows the CF-UPQC series inverter controlling block diagram using synchronous reference frame control theory. In this method, the required value of load phase voltages in $\mathrm{d}$ axis and $\mathrm{q}$ axis is compared with the load voltage and the result is consider as the reference signal. The supply voltage detected $\left(\mathrm{V}_{\mathrm{abc}}\right)$ is detected and transformed into the synchronous dqo reference frame using:

$$
\mathrm{V}_{\mathrm{t}_{-} \mathrm{dqo}}=\mathrm{T}_{\mathrm{abc}}^{\mathrm{dqp}} \mathrm{V}_{\mathrm{t}_{-} \mathrm{abc}}
$$




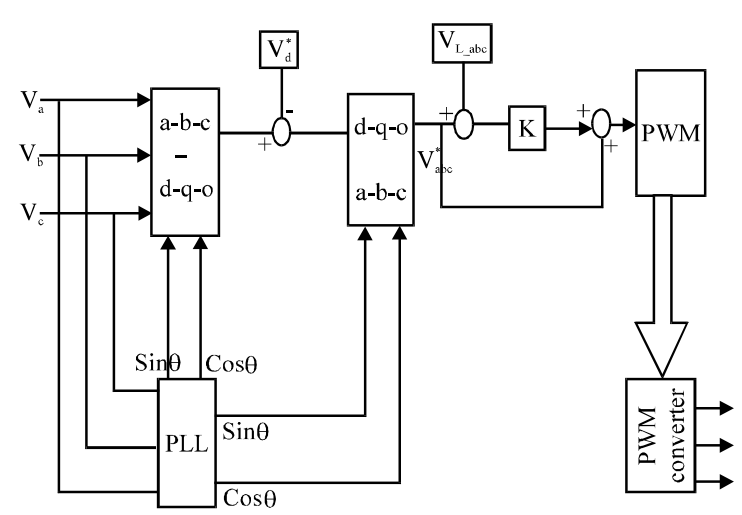

Fig. 5: Control system of the series CF-UPQS

The compensating reference voltage in the synchronous dqo reference frame is defined as:

$$
\mathrm{V}_{\mathrm{sf}_{-} \mathrm{dqo}}^{\mathrm{ref}}=\mathrm{V}_{\mathrm{t}_{-} \mathrm{dqo}}-\mathrm{V}_{\mathrm{t}_{-} \mathrm{dqo}}^{\exp }
$$

The compensating reference voltage in Eq. 8 is then transformed back into the $\left(a_{-} b_{c} c\right)$ reference frame. Resulted reference voltage $\left(\mathrm{V}_{\mathrm{fa}}^{*}-\mathrm{V}_{\mathrm{fc}}^{*}\right)$ and the output current of shunt inverter $\mathrm{V}_{\mathrm{fa}}-\mathrm{V}_{\mathrm{fc}}$ are fed to the hysteresis band controller. The required controlling pulses are generated and the required compensation voltage is generated by the series inverter.

\section{SIMULATION RESULTS}

The proposed system is simulated by Matlab software. In Fig. 6, the simulation of the matrix converter operation without input capacitor is shown. Here, the line voltage is $440 \mathrm{~V}$ and the supply current is $200 \mathrm{~A}$. In this simulation, the input current wave shape is non sinusoidal and it contains harmonics. The simulation time starts from $0.02-0.085 \mathrm{sec}$. Consider the simulation time is from $0.025-0.045 \mathrm{sec}$ as the one cycle of the current wave form. Here, the wave shape of this current is non sinusoidal and it contains harmonics. Figure $6 \mathrm{a}$ shows that the input voltage is harmonic free. Figure $6 \mathrm{~b}$ shows the input current wave form of the matrix converter. Figure $6 \mathrm{c}$ shows the load voltage of the matrix converter output. Figure $6 \mathrm{~d}$ shows the load current applied to the load.

Here, the load current is resistive load. Figure $7 \mathrm{a}$ shows the matrix converter output voltage. Simulation result shows that the matrix output voltage contains harmonics. Figure $7 \mathrm{~b}$ shows the input current of series active filter part. This simulation shows that the
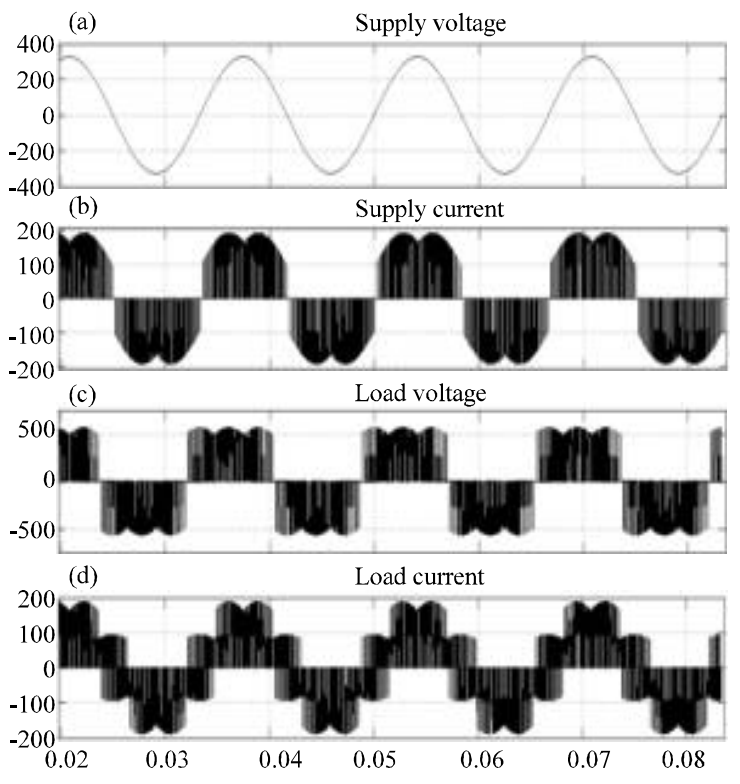

Fig. 6: a) System voltage $\left(V_{S}\right)$; b) Source current $\left(I_{S}\right)$; $)$ Load voltage $\left(V_{L}\right)$ and d) Load current $\left(I_{L}\right)$ without filter

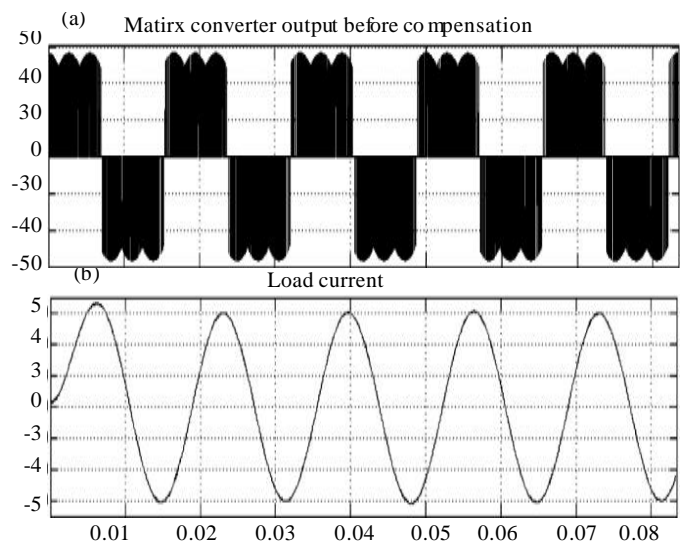

Fig. 7: a) Matrix converter output voltage before compensation and b) Input load current of series active filter

series active filter takes the current sinusoidal. The matrix converter output voltage is $440 \mathrm{~V}$. Figure 8a shows the total harmonic distortion in the source voltage. There is no harmonic present. Figure $8 \mathrm{~b}$ shows the total harmonic distortion in the matrix converter output. The matrix converter produced $60 \%$ of voltage harmonics. In Fig. $8 \mathrm{c}$, the THD is reduced at $1 \%$ by the proposed system. Figure 9 shows the matrix converter is affected by swell. The voltage swell is present from $0.03-0.05 \mathrm{sec}$. The matrix converter reflects the input supply variations to the output supply. Figure 9a 

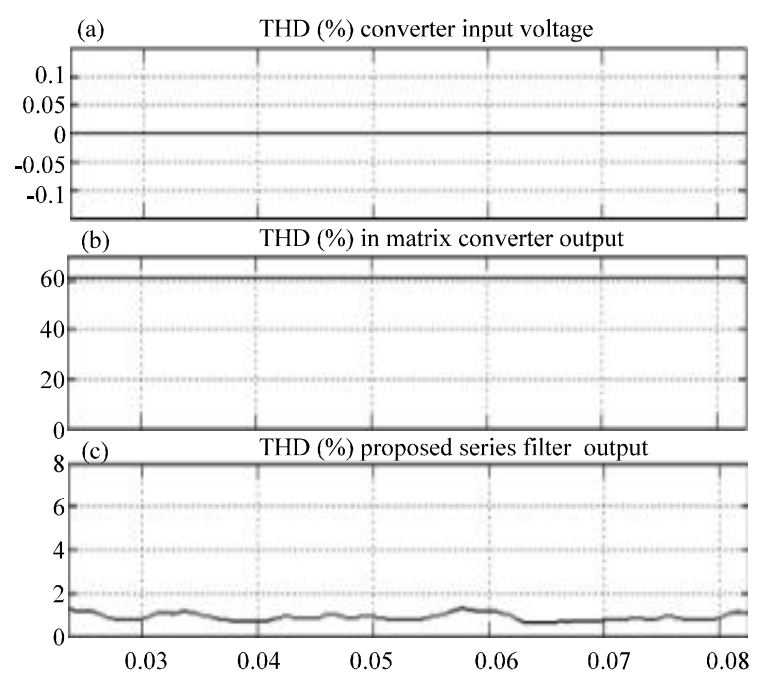

Fig. 8: a) Total harmonic distortion in matrix converter input voltage; b) Total harmonic distortion in matrix converter and c) Total harmonic distortion in matrix converter output current
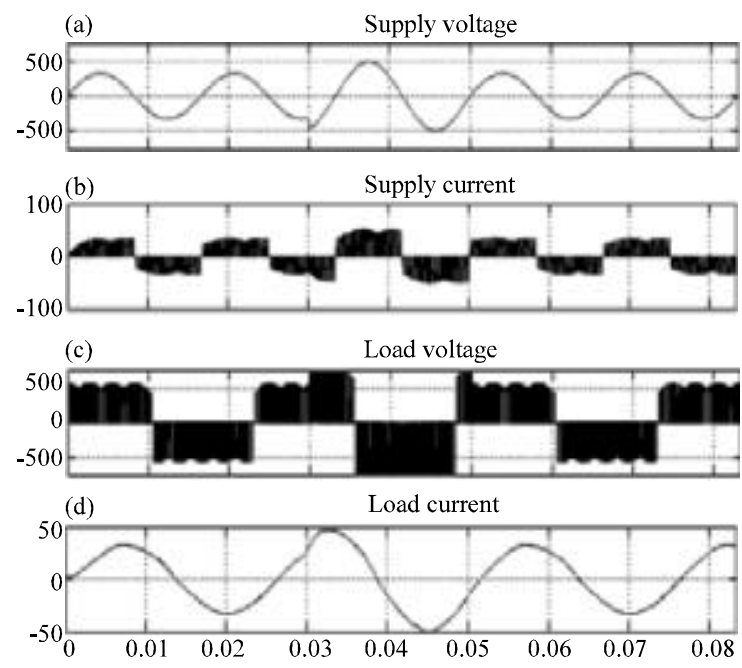

Fig. 9: (a) Voltage swell in matrix converter input; b) Supply current before compensation; c) Matrix converter output voltage and d) Matrix converter output current without UPQC

shows the supply input with sag voltage. Figure $9 \mathrm{~b}$ shows that the supply current drawn by load is also increased. Figure 9c shows the input voltage variations directly affected by the output voltage. When the sag voltage occurs, the load current is also increased without compensation and is given in Fig. 9d. After the proposed compensation (UPQC), series active filter eliminates the swell problem and maintain the power quality in the matrix converter output as shown in

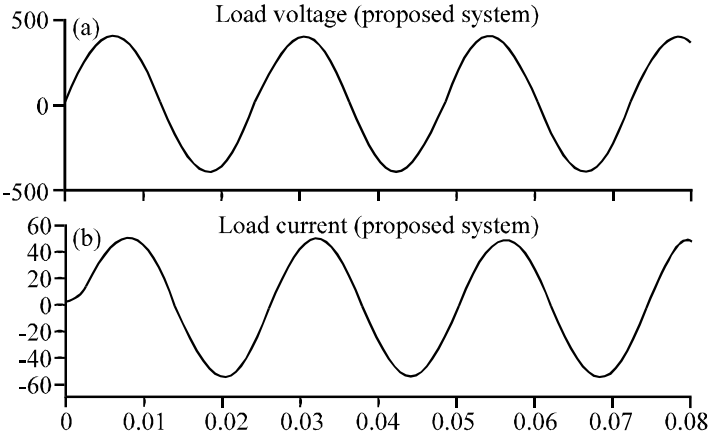

Fig. 10: a) Voltage swell occur in matrix converter output voltage and b) Current with UPQC based compensation

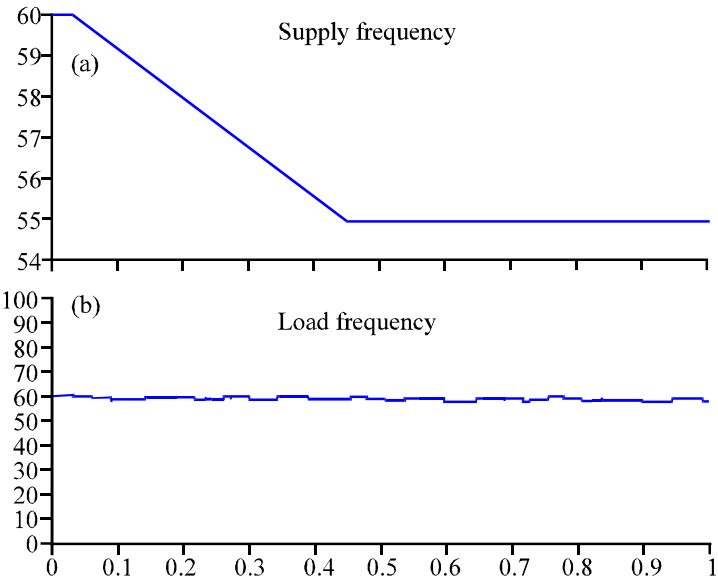

Fig. 11:a) Supply frequency falls below the power quality limit and b) Output load frequency with conventional PI controller based compensation

Fig. 10a, b. Figure 11 shows the system response when the supply frequency is decreased below the power quality limits. It can be seen in Fig. 11a that the frequency decreases from $60-55 \mathrm{~Hz}$, the PI control system regulates the load frequency as constant. As shown in Fig. 11b, the supply frequency varies but the output frequency remains almost constant. Frequency variation starts from $0-0.4 \mathrm{sec}$ linearly. Figure $12 \mathrm{a}$ shows the system response.

The supply frequency is increased above the power quality limits. It can be seen that the frequency increases from $60-65 \mathrm{~Hz}$. The PI system regulates the load frequency to a constant level. The frequency variation starts from $0-0.45 \mathrm{sec}$ linearly. From Fig. 12b, it can be inferred that the output frequency is almost constant even when the supply varies. Figure 13 shows the system response when the supply frequency is decreased below the power quality limits. It can be seen 


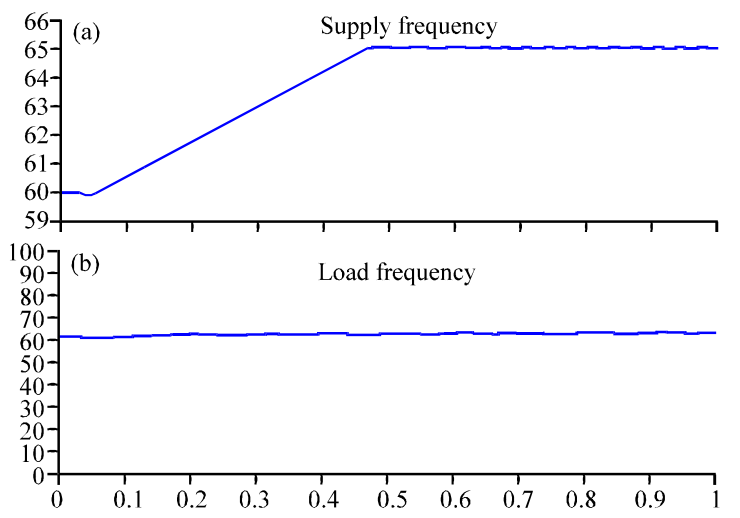

Fig. 12: a) Supply frequency rises above the power quality limit and b) load frequency with conventional PI controller based compensation

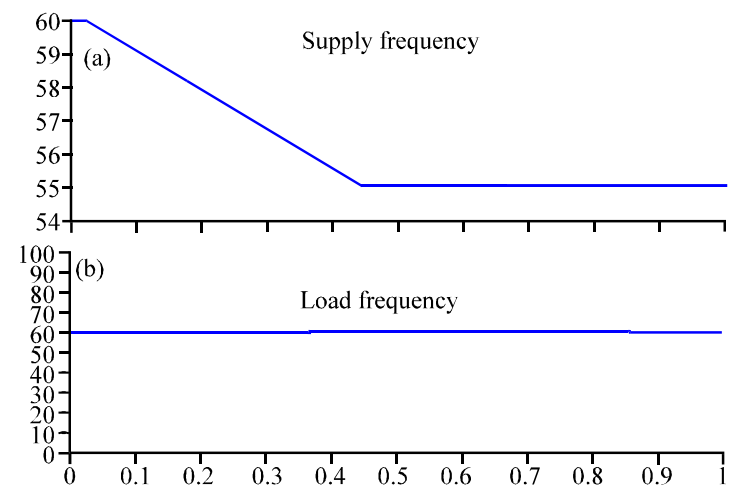

Fig. 13: a) Supply frequency falls below the power quality limit and b) output load frequency with proposed controller based compensation
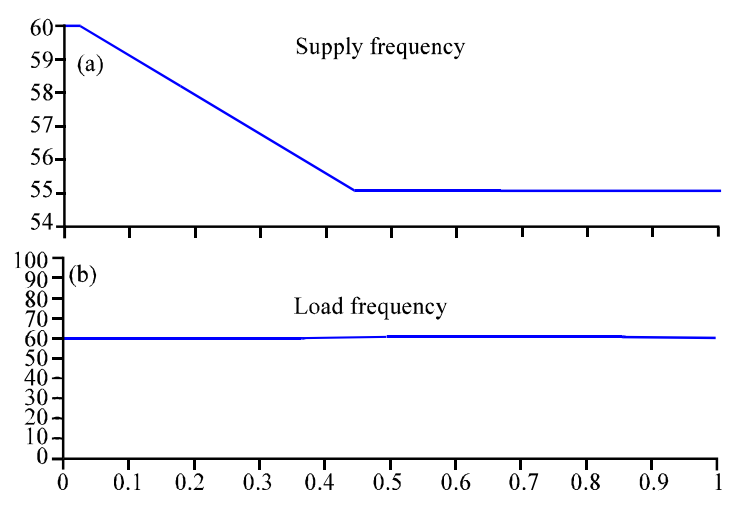

Fig. 14: a) Supply frequency rises above the power quality limit and b) Load frequency with proposed fuzzy controller based compensation

in Fig. 13a that the frequency decreases from $60-55 \mathrm{~Hz}$, the proposed system regulates the load frequency constant. As shown in Fig. 13b, the supply frequency varies but the output frequency remains constant. Frequency variation starts from $0-0.4$ sec linearly. Figure 14a shows the system response. The supply frequency is increased above the power quality limits. It can be seen that the frequency increases from $60-65 \mathrm{~Hz}$. The proposed system regulates the load frequency to a constant level. The frequency variations starts from $0-0.45 \mathrm{sec}$ linearly as shown in Fig. 14a. From Fig. 14b, it can be inferred that the output frequency is almost constant even when the supply varies.

\section{CONCLUSION}

This study has presented a model of custom power equipment, namely constant frequency unified power quality conditioner with ANN control (CF-UPQC). The study illustrates the operation and control of a CFUPQC. This device is connected in between source and load. When a unbalanced and frequency sensitive load is supplied through CF-UPQC, it will regulate the supply voltage, supply frequency and eliminates harmonics. The main aim of the CF-UPQC is to regulate the supply frequency at the load terminal. The proposed method can regulate the supply frequency efficiently using matrix converter. The simulation results showed that the proposed system has the ability to control almost compensates all the power quality issues compared to PI controller.

\section{REFERENCES}

Benslimane, T., K. Aliouane and B. Chetate, 2006. Voltage and current disturbances eliminationwith reactive power compensation using unified power quality conditioner. Int. Symp. Power Electron., 3: 24-28.

Chung, M. and Deohan, 2005. Analysis and control of UPQC and its de link power by use of P-Q instantaneous power theory. Proceedings of the 1st International Conference on Power Electronics System, May 2005, USA., pp: 43-53.

Graovac, D., V. Katic and A. Rufer, 2000. Power quality compensation using universal power quality conditioning system. IEEE Power Eng. Rev., 20: $58-60$.

Jeno Paul, P., I. Jacob Raglend and T. Ruban Deva Prakash, 2011. Constant frequency-unified power quality conditioner. Proceedings of the International Conference on Emerging Trends in Electrical and Computer Technology, March 23-24, Nagercoil, India, pp: 1-8. 
Mauricio, A. and R.M. Fernandes, 2009. A unified power quality conditioner with voltage sag/swell compensation capability. Proc. Braz. Power Electron. Conf., 4: 218-224.

Mishra, S., C.N. Bhende and B.K. Panigrahi, 2008. Detection and classification of power quality disturbances using s-transform and probabilistic neural network. IEEE Trans. Power Delivery, 23: $280-287$.
Monedero, I., C. Leon, J. Ropero, A. Garcia, J.M. Elena and J.C. Montano, 2007. Classification of electrical disturbancesin real time using neural networks. Trans. Power Delivery, 22: 1288-1296.

Watanabe, E.H. and M. Aredes, 2002. Power quality considerations on shunt/series current and voltage conditioners. Proceedings of the 10th International Conference on Harmonics and Quality of Power, Oct. 6-9, USA., pp: 595-600. 